\title{
A RECONTEXTUALIZAÇÃO COMO ESTRATÉGIA DE INTELIGIBILIDADE NO JORNALISMO CIENTÍFICO
}

Luana Macieira Barbosa

Resumo: Para entender como se dá a inteligibilidade de discursos do campo do jornalismo científico, este artigo visa a observar o processo de recontextualização que transforma artigos científicos em matérias jornalísticas. Para isso, analisamos um artigo científico escrito por um pesquisador e professor da UFMG e a matéria jornalística referente a este artigo e que foi publicada no Boletim UFMG, jornal semanal produzido pelos jornalistas da universidade. O processo de recontextualização foi observado por meio de categorias de análise elaboradas por Ciapuscio (1997). Pudemos observar que os jornalistas utilizam diversas estratégias de recontextualização para fazer com que seus textos sejam compreendidos pelo público, e que textos mais inteligíveis permitem o desenvolvimento de uma cultura científica que dota os cidadãos de pensamento crítico sobre temas relacionados à ciência.

Palavras-chave: Recontextualização. Divulgação científica. Jornalismo científico.

\section{RE-CONTEXTUALIZATION AS STRATEGY OF INTELIGIBILITY IN SCIENTIFIC JOURNALISM}

\begin{abstract}
To understand how intelligibility occurs in discourses from the field of scientific journalism, this paper observes the process of re-contextualization that transforms scientific papers in journalistic articles. We analyzed one paper written by a researcher from UFMG and the journalist article that was written according to this paper and published in Boletim UFMG, a weekly newspaper produced by journalists from the university. The process of re-contextualization was observed in texts according to categories created by Ciapuscio (1997). We observed that journalists use several strategies of re-contextalization to guarantee that their texts are understood by public, and that texts more understandable help in the development of a scientific culture that gives the power of critical thinking for citizens in themes related to science.
\end{abstract}

Keywords: Re-contextualization. Scientific journalism. Scientific divulgation. 


\section{INTRODUÇÃO}

A consolidação da pesquisa científica no Brasil e a desmitificação do estereótipo do pesquisador foram alguns dos principais fatores que desencadearam o desenvolvimento do jornalismo científico. Esse campo do jornalismo foca seus esforços na divulgação de estudos, pesquisas e produções das diversas áreas da ciência, como tecnologia, biomedicina, engenharia e ciências sociais, por exemplo.

Junto ao processo de ampliação da divulgação de informações de caráter científico, houve um aumento do número de pessoas que buscam esse tipo de conhecimento, uma vez que elas passaram a reconhecer a necessidade de terem acesso às informações sobre ciência, em particular àquelas que afetam diretamente suas vidas, como novas vacinas e meios de tratamento de doenças, além de novas tecnologias sustentáveis que facilitem o seu dia a dia. O brasileiro passou a ter interesse pela informação sobre ciência e tecnologia (C\&T) que é repassada ao grande público pelos veículos especializados na cobertura de ciência, partindo do princípio de que os órgãos governamentais, as universidades e os institutos de pesquisa são os maiores detentores primários desse tipo de informação.

A Universidade Federal de Minas Gerais (UFMG) é produtora de diversas pesquisas científicas de interesse da sociedade, seja na área de humanas, exatas ou biológicas. Com o intuito de divulgar o conhecimento que é produzido por seus pesquisadores, ela conta com vários veículos de comunicação, como o Boletim UFMG, jornal que é disponibilizado eletronicamente em seu website (www.ufmg.br).

$\mathrm{Na}$ universidade, a produção de matérias de jornalismo científico envolve três fases: entrevistas com os pesquisadores que realizaram o estudo que será divulgado, transcrição dessas entrevistas (que são gravadas em áudio) e, finalmente, a redação dos textos jornalísticos. O texto científico, quando transformado em texto jornalístico, passa por um processo de recontextualização. Trata-se de uma transformação textual que busca transformar as informações sobre ciências inteligíveis para um público que não possui os conhecimentos prévios para compreender temas mais complexos da ciência e que pouco circulam na sociedade.

O jornalismo científico que abordamos neste artigo é descrito por Claudio Bertolli Filho como "um produto elaborado a partir de certas regras rotineiras de jornalismo em geral, que trata de temas complexos de ciência e tecnologia e que se apresenta, no plano linguístico, por uma operação que torna fluida a leitura e o entendimento do texto noticioso por parte de um público não especializado" (BERTOLLI, 2006, p. 3).

Assim, entendermos que o jornalismo científico pode ser considerado um dos principais responsáveis por fazer o conhecimento ultrapassar os muros da comunidade científica, permitindo uma maior democratização do acesso à informação científica. Daí nossos interesses em investigar a recontextualização como processo de transformação textual que ocorre durante a criação de textos de jornalismo científico.

\section{O JORNALISMO CIENTÍFICO E A UFMG}

Segundo Bueno (1985), o jornalismo científico se apropria de características comuns do jornalismo, como a atualidade, a universalidade, a periodicidade e a difusão. Na prática,

... isso significa dizer que ele se define: pela atualidade, ocupando-se de fatos (eventos, descobertas) ou pessoas (cientistas, tecnólogos, pesquisadores) que estejam direta ou indiretamente relacionados com o momento presente; pela universalidade, abrigando os diferentes ramos do conhecimento científico; pela periodicidade, mantendo o ritmo das 
publicações ou matérias [...] e pela difusão, o que pressupõe a sua circulação pela coletividade. (BUENO, 1985, p. 1422)

Isso nos leva a perceber que a maioria das características que definem as matérias jornalísticas podem ser vislumbradas também nas matérias e reportagens de jornalismo científico. No caso da matéria jornalística que serve de objeto de análise deste artigo, as características definidoras do jornalismo se fazem presentes a partir do momento em que o Boletim UFMG, jornal produzido pela universidade, se autodenomina como um veículo jornalístico.

O Boletim UFMG preza pela atualidade, pois se esforça para divulgar matérias sobre artigos científicos recém-publicados pelo seu corpo de pesquisadores; a universalidade aparece quando notamos que ele apresenta matérias de diversas áreas do conhecimento, retratando artigos que foram escritos por pesquisadores das áreas de exatas, humanas, artes, biológicas e ciências sociais aplicadas; a periodicidade pode ser comprovada quando notamos que a publicação do veículo possui uma periodicidade definida (é semanal); a difusão é facilmente observável quando percebemos que as matérias publicadas no Boletim UFMG podem ser lidas por qualquer pessoa que tenha acesso a internet e, além disso, podem ser compartilhadas pelos leitores em suas redes sociais.

O jornalismo científico é visto por pesquisadores da área de comunicação como uma importante ferramenta de divulgação do progresso científico e tecnológico, além de ter funções informativa, educativa, social e cultural. Para Bueno (1985), a primeira função está diretamente relacionada à função do jornalismo em si, que é divulgar fatos de relevância para a sociedade. A função educativa pressupõe uma intenção pedagógica, que é exercida quando o jornalismo científico ensina ciência aos seus leitores. A função social pode ser observada quando o jornalismo científico se preocupa em situar a informação sobre ciências no contexto em que o leitor está inserido, ou seja, o jornalista se preocupa em aproximar o conhecimento científico da vida do leitor. Já a função cultural tem ligação com a dominação cultural que pode ser exercida por esse tipo de jornalismo, uma vez que a posse do conhecimento pode servir como objeto de manipulação.

Quando nos referimos à UFMG, devemos ressaltar que a universidade, por ser pública, precisa divulgar as suas atividades nas áreas de pesquisa, ensino e extensão, atendendo ao princípio de "publicidade" da administração pública. Assim, o Boletim UFMG serve, também, como um veículo que a universidade utiliza para prestar contas dos gastos que realiza com o dinheiro público.

\section{A RECONTEXTUALIZAÇÃO}

O termo recontextualização foi amplamente explicado por diversos autores, entre eles Van Leeuwen (2008), linguista que afirmava que a recontextualização era um processo que levava em conta agentes envolvidos em certas práticas sociais. $\mathrm{O}$ autor, que ajudou a divulgar o conceito de recontextualização, apontava que esta atividade envolvia quatro processos de transformação discursiva: substituição, anulação, rearranjamento e adição.

A substituição ocorre quando o texto sofre alterações para melhor se adaptar ao novo contexto social da prática comunicativa. A anulação é a supressão ou apagamento de elementos que não são mais necessários no novo contexto comunicativo. O rearranjo é a mudança na ordem em que os elementos aparecem no texto (mudança da importância dada aos seus elementos) e a adição é a inclusão de novos dados ou informações que são necessários à nova troca comunicativa. 
Neste trabalho, vamos considerar, para o entendimento do processo de recontextualização do discurso de divulgação científica, as categorias elaboradas por Ciapuscio (1997), que vê o processo de recontextualização no jornalismo como uma reformulação de artigos científicos. A autora entende o artigo científico e a matéria jornalística como discursos e afirma que os artigos, apesar de serem gêneros secundários, devido às suas complexidades, são discursos primários, pois foram os primeiros a serem produzidos. Por outro lado, ela afirma que as matérias de jornalismo científico são discursos secundários, uma vez que foram produzidos posteriormente, tendo o discurso primário (artigo científico) como base.

Calsamiglia e Cassany (2001) também apontam que os textos, ao mudarem de um contexto para o outro, sofrem transformações que envolvem atividades de resumo, reformulação e expansão.

[...] o normal é que a responsabilidade da divulgação obrigue a transformar de um texto a outro, do 'discurso primário' (que formula um conhecimento novo) a 'discursos secundários' (que o divulgam), ativando operações diversas de reelaboração que pressupõem selecionar o que é relevante, resumi-lo, reformulá-lo ou expandir determinados aspectos não desenvolvidos no primeiro discurso. (CALSAMIGLIA; CASSANY, 2001, p. 3. Tradução minha)

Calsamiglia (1997) aponta que o contexto deve ser levado em conta na divulgação científica porque a mudança de campo onde são produzidos os discursos têm consequências no modo como estes são feitos. Ela afirma que o primeiro campo considerado por nós faz referência às esferas onde ocorrem as práticas geradoras do discurso científico, com textos repletos de especificidades de léxico e terminologias próprias, características que os distinguem de textos mais gerais. Enquanto isso, o segundo discurso é aquele com léxico comum, apresentando textos heterogêneos, com temas que podem ser associados a conteúdos típicos da vida da maioria das pessoas e "recursos que tornam mais fácil, amena e inteligível a transmissão e representação dos saberes" (CALSAMIGLIA, 1997, p. 5. Tradução minha).

Noccioli e Cataldi (2011) mostram que a recontextualização do conhecimento científico é uma espécie de "recriação" deste conhecimento, porém as autoras destacam

\begin{abstract}
o fato de essa prática discursiva não ser simplesmente um resumo ou redução aleatória de dados científicos, mas sim uma habilidade em selecionar, reorganizar e reformular as informações de caráter técnico para leitores com interesses e objetivos diversos, no processo de compreensão dos fatos científicos. (NOCCIOLI; CATALDI, 2011, p.40)
\end{abstract}

Já Motta-Roth (2010) vê a recontextualização como uma atividade da mídia especializada em divulgação científica. Segundo ela, a recontextualização envolve o deslocamento do discurso da ciência de um contexto de produção primário (onde o artigo científico foi escrito) para um contexto secundário (onde a matéria jornalística é feita).

Os significados originalmente privilegiados e privilegiantes do artigo são selecionados, simplificados, condensados e elaborados em outro contexto de práticas interativas, por meio de paráfrase, substituições de termos especializados por outros de uso cotidiano, analogias e comparações. (MASARANI; MOREIRA, 2005 apud MO'T'TA-ROTH, 2010, p. 163)

Segundo a autora, a recontextualização implica confluência entre dois textos, gerando uma espécie de fluxo entre discursos, gêneros e textos. Neste fluxo, o artigo científico acaba sendo reposicionado e sofrendo uma mudança de autor: sai o escritor/especialista/cientista que escreve para um leitor-especialista e entra o escritor/jornalista que escreve para um leitor não-especialista que, aos poucos, é recontextualizado da esfera midiática para a esfera científica. 
Cassany e López (2000) resumem o conceito de recontextualização como um processo de mudanças que ocorrem devido à necessidade de alterações nas redes conceituais dos assuntos de que tratam o artigo científico e a matéria jornalística. Para os autores, o conhecimento que está expresso no artigo científico pode ser entendido como uma rede de conceitos especializados, onde cada nó da rede, referente a algo relacionado ao conceito, está ligado a outros nós. Segundo eles, a recontextualização é o processo que reelabora esta rede conceitual de maneira a torná-la acessível ao público leitor da matéria jornalística. Dessa forma,

[...] a rede conceitual original, elaborada dentro de um marco de referência (o discurso científico), com certas funções (dar explicações científicas para a realidade) e para interlocutores restritos (a comunidade científica) se transforma para poder significar de maneira relevante o que é mais essencial em seu conteúdo, em uma segunda situação comunicativa: fora dos marcos de referência especializados, com funções informativas mais frágeis e para interlocutores amplos e não qualificados. Denominamos recontextualização o conjunto de operações implicadas neste processo de transformação. (CASSANY; LÓPEZ, 2000, p. 8. Tradução minha)

Desta maneira, Cassany e López percebem dois processos na transformação dos discursos de divulgação científica: a redução e a inclusão. Para eles, a redução ocorre quando o tema perde alguns desses nós conceituais que não são necessários para a compreensão pelo público alvo do texto produto da recontextualização. Neste sentido, o texto original fica mais fácil de ser compreendido por aqueles que não tinham conhecimento para entender os nós que foram retirados da rede conceitual. $\mathrm{Na}$ recontextualização do artigo científico, podemos exemplificar o procedimento com a retirada de todos os nós da rede conceitual que abordavam a metodologia da pesquisa e que não aparecem na matéria jornalística.

Já a inclusão é o processo que cria novos nós temáticos na rede do conhecimento científico, buscando aproximá-la do leitor da matéria jornalística. Se um artigo fala de um novo medicamento para uma doença, por exemplo, são inclusos na rede conceitual nós que fazem referência a questões sobre saúde e prevenção a esta doença, aspectos que não foram tratados no artigo científico.

As transformações das redes conceituais observadas por Cassany e López (2000) podem ser melhor visualizadas na figura a seguir, reprodução de uma figura publicada em um texto de Cassany, onde este exemplifica as redes conceituais dos discursos de comunicação e divulgação científica sobre alimentos transgênicos

Figura 1 - Redes conceituais de Cassany.

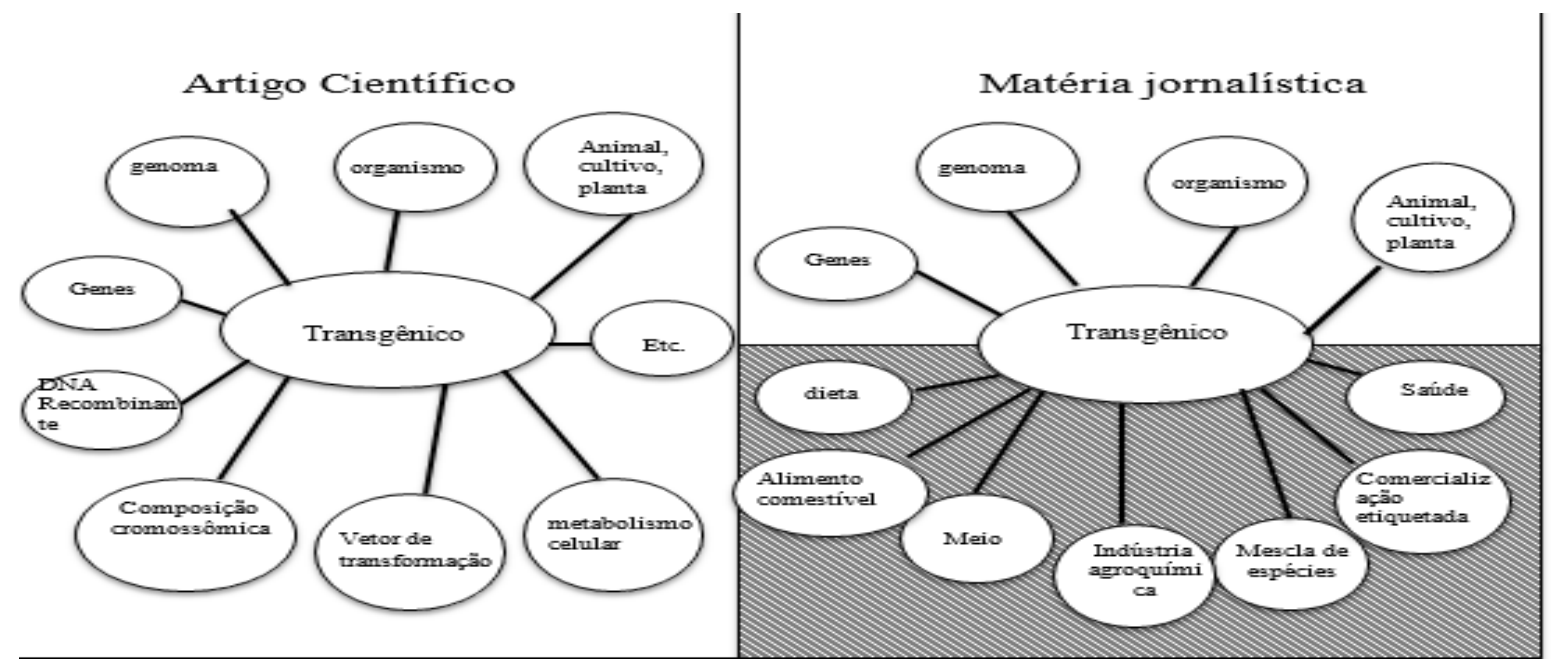


Fonte: CASSANY, Daniel. Análisis de la divulgación científica: modelo teórico y estratégias divulgativas. In: Texto, linguística y cultura. XIV Congreso de la Sociedad Chilena de Linguística.

Comunicaciones seleccionadas. Osorno: Editorial Universidad de Los Lagos, 2003, p. 57-80.

No caso da reprodução da figura de Cassany (2003), vemos que nós temáticos como dieta e saúde não apareciam no artigo científico, mas foram inclusos na matéria jornalística com o objetivo de aproximá-la do leitor deste último texto.

Ciapuscio (1997) também entende que o processo de recontextualização do texto científico em texto jornalístico envolve procedimentos de transformação textuais, os quais ela chama de redução, expansão e variação. Aqui, fazemos um apanhado desses procedimentos, que servirão como categorias de análise dos textos que integram o corpus deste estudo.

\section{A redução}

Este procedimento caracteriza-se pela supressão ou omissão de dados ou de informações que estavam presentes no primeiro texto (artigo científico), mas não são necessários no texto produto da recontextualização (a matéria jornalística). Ciapuscio (1997) afirma que o texto de divulgação científica conta apenas com a informação mais importante da pesquisa, omitindo informações como a metodologia do estudo e seu referencial teórico, por exemplo.

$\mathrm{Na}$ redução fica claro o modo como as informações de interesse do público primário não são as mesmas do público do texto secundário. Se a um pesquisador, no momento em que depara com um artigo científico, interessa conhecer o passo a passo de uma pesquisa, as hipóteses de tal estudo e a fundamentação teórica usada, ao leitor da matéria jornalística importam as conclusões da pesquisa e as suas consequências práticas. Tais informações de interesse do leitor da matéria aparecem no lead do tex to jornalístico que, como já apontado anteriormente, constitui-se no parágrafo inicial do texto e condensa as informações mais importantes da matéria.

Como estratégias divulgativas presentes no processo de redução, podemos destacar a classificação e o resumo. A primeira consiste em agrupar conceitos de forma a aproximá-los do leitor, enquanto o resumo é a supressão de informações mais abstratas que não são essenciais na matéria jornalística.

\section{A expansão}

Ocorre por meio da inclusão, no texto final, de informações ou dados que não aparecem no texto fonte. Ciapuscio (1997) aponta a definição como uma das formas de se realizar o procedimento de expansão. Já Noccioli e Cataldi (2011, p. 41) dizem que

[...] a expansão constitui-se por meio de determinadas estratégias discursivas, como a substituição de um termo por outro, sem prejuízos semânticos; pela explicitação de algum conhecimento compartilhado pelos participantes; bem como pela apresentação de algum tipo de informação nova que contribui pra que o leitor estabeleça relações de sua vida diária com o conhecimento científico.

Ainda como estratégias divulgativas do processo de expansão podemos citar a exemplificação e o uso de citações. Enquanto esta última busca conferir autoridade e credibilidade ao discurso, colocando a informação na voz do especialista no assunto, a exemplificação aproxima o assunto do leitor ao mostrar que algo que está mais próximo desse leitor pode ser associado e comparado àquilo que foi dito.

\section{A variação}

Este procedimento caracteriza-se pelas mudanças do vocabulário que, por meio de 
diversas estratégias discursivas e textuais, sofre alterações para se tornar mais acessível ao público do texto produto da recontextualização (a matéria de jornalismo científico). No caso da transformação do artigo científico em matéria jornalística, a variação pode ser facilmente observada na substituição de termos técnicos do artigo científico. Esses termos, inteligíveis apenas pelo público alvo do artigo científico, são transformados em palavras pertencentes a um vocabulário mais amplo, que vai além do campo do assunto tratado no artigo.

É importante lembrarmos que a variação se manifesta, também, de outras maneiras, como por meio da mudança da modalidade enunciativa, por exemplo, e do uso de estratégias divulgativas como a metáfora, que pode ser usada na matéria jornalística para substituir vocábulos mais complexos e menos inteligíveis. "Para o público não especializado, a metáfora é um recurso que permite conceitualizar fenômenos abstratos ou excessivamente técnicos por meio de associações com objetos ou aspectos do mundo cotidiano"1 (CIAPUSCIO, 2007, p. 4. Tradução minha).

Quando falamos da metáfora, é importante ressaltarmos que, além de estratégia divulgativa de variação (ocorre a troca de um vocabulário por outro) ela pode funcionar como estratégia de expansão (um conceito complexo pode ser explicado por meio de uma metáfora que vai além do conceito inicial explicitado no artigo científico). Ao ser considerada como um recurso múltiplo, que pode aparecer em dois tipos diferentes de procedimentos de transformação textual (variação e expansão), a metáfora apresenta-se como estratégia dinâmica de recontextualização, exercendo importante papel nos textos de divulgação científica.

1 “... la metafora es un recurso que permite concepctualizar fenómenos abstractos o excesivamente técnicos mediante asociaciones con objetos o aspectos del mundo cotidiano" (CIAPUSCIO, 2007, p. 4).

\section{UMA \\ ANÁLISE \\ RECONTEXTUALIZAÇÃO}

DE

Para entender como ocorre o processo de recontextualização no jornalismo científico praticado pela UFMG, decidimos analisar um texto que foi publicado no Boletim UFMG, o jornal semanal da universidade que é disponibilizado apenas em versão on-line, pelo endereço https:// ufmg.br/comunicacao/publicacoes/boletim

A matéria jornalística escolhida foi publicada em 22 de abril de 2019, na edição de número 2055, Ano 45, com o título "Flor do Nordeste". Tratase de um texto que aborda a descoberta de uma nova espécie de planta da família da acerola. O estudo foi publicado no periódico PhytoKeys, sob o título Taxonomic revision of Mcvaughia W. R. Anderson (Malpighiaceae): notes on vegetative and reproductive anatomy and the description of a new species.

Figura 2 - reprodução da página do Boletim UFMG.

\section{FLOR do NORDESTE}

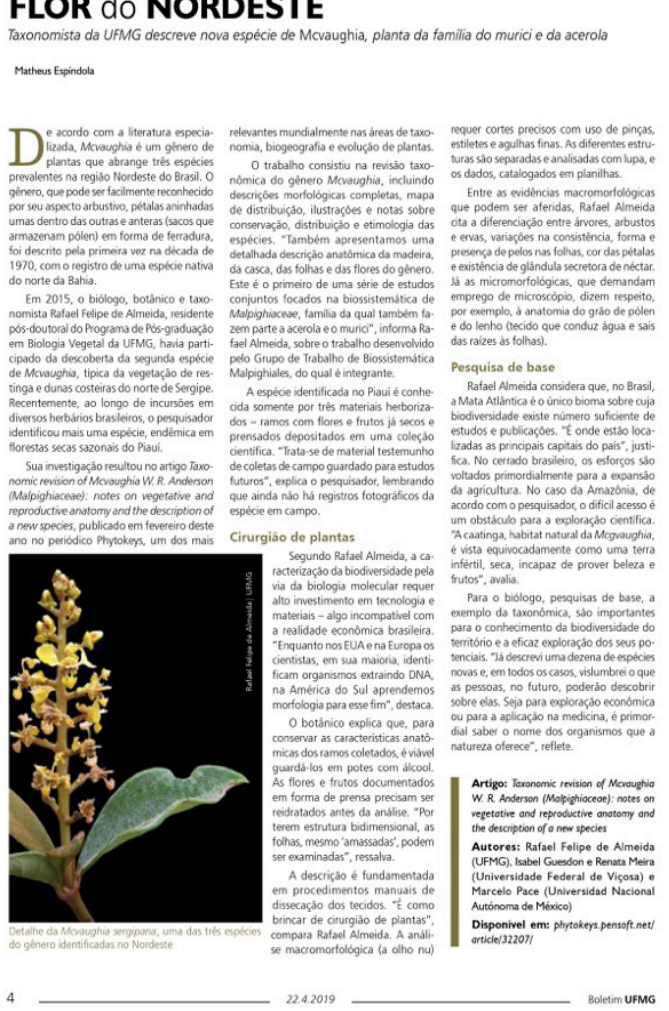

Fonte: Boletim UFMG, 2019, p. 4. 
Em nossa análise, decidimos considerar as categorias criadas por Ciapuscio (1997), que enquadram as mudanças ocorridas nos textos como ações de recontextualização. Vamos observar como aparecem, na matéria jornalística selecionada, as estratégias divulgativas de redução, expansão e variação, categorias de análise que a autora criou de acordo com as ideias iniciais de Van Leeuwen (1998). No quadro a seguir, sistematizamos as categorias que foram consideradas em nossas análises.

Figura 3 - quadro com as categorias de análise.

\begin{tabular}{|c|c|}
\hline \multicolumn{2}{|c|}{ Categorias de análise de Ciapuscio } \\
\hline \multirow{4}{*}{ Redução } & Classificação \\
\cline { 2 - 2 } & Resumo \\
\cline { 2 - 2 } & Anulação \\
\hline \multirow{4}{*}{ Expansão } & Definição \\
\cline { 2 - 2 } & Exemplificação \\
\cline { 2 - 2 } & Uso de citação \\
\hline \multirow{3}{*}{ Variação } & Metáforas \\
\cline { 2 - 2 } & Denominação \\
\hline
\end{tabular}

Fonte: elaborado pela autora.

A primeira mudança referente ao processo de recontextualização envolvido na produção da matéria jornalística que escolhemos analisar pode ser observada nos títulos dos dois textos. O título do texto jornalístico (1) já conta com a técnica de redução na modalidade resumo, uma vez que ele resume, em apenas uma frase, a ideia central do estudo que foi desenvolvido pelos três pesquisadores.

No caso dos títulos, a recontextualização é importante porque funciona como delimitadora dos objetivos dos textos junto aos seus leitores. $\mathrm{Na}$ matéria jornalística, o autor precisa atrair a atenção do leitor para que ele tenha interesse em ler o texto até o final. Neste caso, o jornalista optou por trazer a nova espécie descoberta para perto da vida das pessoas, destacando que se trata de uma planta da família do murici e da acerola, espécies muito conhecidas (no caso do murici, o fruto é bastante comum nas regiões Norte e Nordeste do país).

O resumo do tema da pesquisa, que é tratado no título da matéria jornalística de forma simples e objetiva, aparece em um espaço bem delimitado do artigo científico. Sabemos que o artigo científico possui uma estrutura fixa e pré-determinada (com resumo, introdução, metodologia, análise e conclusão). No caso deste artigo científico, podemos dizer que a informação que aparece em seu resumo serviu de base para a redação do título da matéria jornalística que, em apenas uma linha, busca prender a atenção do leitor e resumir todo o trabalho realizado pelo grupo de pesquisadores.

(1) Flor do Nordeste. Taxonomista da UFMG descreve nova espécie de Mcvaughia, planta da família do murici e da acerola.

O texto da matéria jornalística tem início com as estratégias de expansão por definição e variação por metáfora. Assim como o título, o primeiro parágrafo tem o objetivo de despertar o interesse do leitor em ler o texto e resumir o assunto que será tratado. Neste caso, o jornalista realiza uma definição da espécie Mcvaughia (2), utilizando uma metáfora para descrever a planta. Por se tratar de uma planta que acabou de ser "descoberta", o jornalista descreve o seu formato por meio de uma comparação que pode ser facilmente imaginada pelo leitor. Para isso, ele exemplifica que os sacos de pólen da planta possuem "formato de ferradura" (3).

(2) [...] Mcvaughia é um gênero de plantas que abrange três espécies prevalentes na região Nordeste do Brasil.

(3) O gênero, que pode ser facilmente reconhecido por seu aspecto arbustivo, pétalas aninhadas umas dentro das outras e anteras (sacos que armazenam pólen) em forma de ferradura $[\ldots]$ 
No segundo parágrafo do texto, o jornalista se preocupa em situar a trajetória acadêmica do pesquisador, destacando que ele é residente de pósdoutorado na UFMG (4), universidade responsável pelo veículo jornalístico onde a matéria foi publicada. No artigo científico, não há espaço de destaque para a trajetória do pesquisador e a sua filiação aparece apenas em uma nota de rodapé, como é de praxe em artigos acadêmicos. Além disso, enquanto no artigo científico podemos observar a filiação dos quatro pesquisadores que integram o grupo responsável pelo estudo, na matéria é citado apenas aquele vinculado à UFMG. Tal decisão vai ao encontro da linha editorial do Boletim UFMG, que foca seus esforços em divulgar as pesquisas que foram realizadas pelos membros da sua comunidade acadêmica.

Aqui, mais do que explicar a linha de pesquisa onde o estudo foi desenvolvido, busca-se também promover o Programa de Pós-graduação em Biologia Vegetal da universidade. O Boletim UFMG, jornal onde coletamos esta matéria jornalística, além de mostrar à sociedade como a universidade gasta o dinheiro público, também serve como veículo de propaganda. Desta maneira, este destaque ao programa onde o estudo foi desenvolvido acaba por promover uma de suas linhas de pesquisa.

(4) Em 2015, o biólogo, botânico e taxonomista Rafael Felipe de Almeida, residente pós-doutoral do Programa de Pósgraduação em Biologia Vegetal da UFMG, já havia participado [...]

Em vários momentos do texto jornalístico, notamos o uso de expansão na modalidade citação quando o pesquisador quer dar a sua opinião pessoal sobre algo [(5), (6) e (7)]. Estas opiniões não possuem espaço no artigo científico, texto onde aparecem apenas informações técnicas e que foram previamente verificadas durante o estudo científico.
É importante notarmos que, neste caso, o jornalista utiliza o discurso direto do pesquisador, colocando a sua fala entre aspas. A opção por colocar esta informação na voz do especialista tem objetivos claros. Quando opta por colocar a fala do entrevistado entre aspas, o jornalista pretende indicar que aquilo realmente foi dito pela fonte jornalística, distanciando-se do que foi dito e, consequentemente, eximindo-se de qualquer responsabilidade sobre aquela fala ou opinião emitida.

(5) "Enquanto nos Estados Unidos e na Europa os cientistas, em sua maioria, identificam organismos extraindo DNA, na América do Sul aprendemos morfologia para esse fim".

(6) "A caatinga, habitat natural da Mcgvaughia, é vista equivocadamente como uma terra infértil, seca, incapaz de prover beleza e frutos".

(7) Seja para exploração econômica ou para a aplicação na medicina, é primordial saber o nome dos organismos que a natureza oferece.

No primeiro subtítulo da matéria ("Cirurgião de plantas") nos deparamos com fenômenos de redução e de expansão. Esta retranca ${ }^{2}$ tem como objetivo explicar como se dá o trabalho taxonômico de plantas e a metodologia da pesquisa, ou seja, as etapas do estudo feitas pelo pesquisador para chegar à descoberta da nova espécie.

No artigo científico, a metodologia é descrita por meio de diversas imagens da planta, de suas folhas e demais componentes. Essas imagens, muitas feitas por microscópio, apresentam características que são inteligíveis apenas para os estudiosos do campo. Assim, a metodologia da pesquisa, que ocupa mais de 10 páginas no artigo científico, foi rapidamente abordada na matéria jornalística. Nesta última, além de abrir mão das imagens feitas pelo microscópio e usar uma imagem

2 Segundo o Manual de Redação da Folha de S. Paulo (2001), retranca é um termo genérico que designa cada unidade de texto em um jornal. Trata-se de cada subtítulo do texto. 
da planta em tamanho real, o jornalista usou estratégias de redução na modalidade resumo para explicar o passo a passo do estudo.

Dessa forma, os trechos referentes à metodologia no artigo científico aparecem na matéria recontextualizados em quatro parágrafos curtos. Neles, vemos a descrição de conceitos do campo da biologia (8) e procedimentos técnicos (9) que foram realizados e que não são claros àqueles que não dominam o campo do conhecimento. Em se tratando dos procedimentos realizados durante a pesquisa, estes são minunciosamente descritos no artigo científico, com textos e imagens, conforme exemplificado na FIGURA 3.

(8) Entre as evidências macromorfológicas que podem ser aferidas, Rafael Almeida cita a diferenciação entre árvores, arbustos e ervas, variações na consistência, forma e presença de pelos nas folhas, cor das pétalas e existência de glândula secretora de néctar. Já as micromorfológicas, que demandam emprego de microscópio, dizem respeito, por exemplo, à anatomia do grão de pólen e do lenho (tecido que conduz água e sais das raízes às folhas.

(9) [...] para conservar as características anatômicas dos ramos coletados, é viável guarda-los em potes com álcool. As flores e frutos documentados em forma de prensa precisam ser reidratados antes da análise.

Figura 3 - Imagens feitas pelo microscópio e presentes no artigo científico.

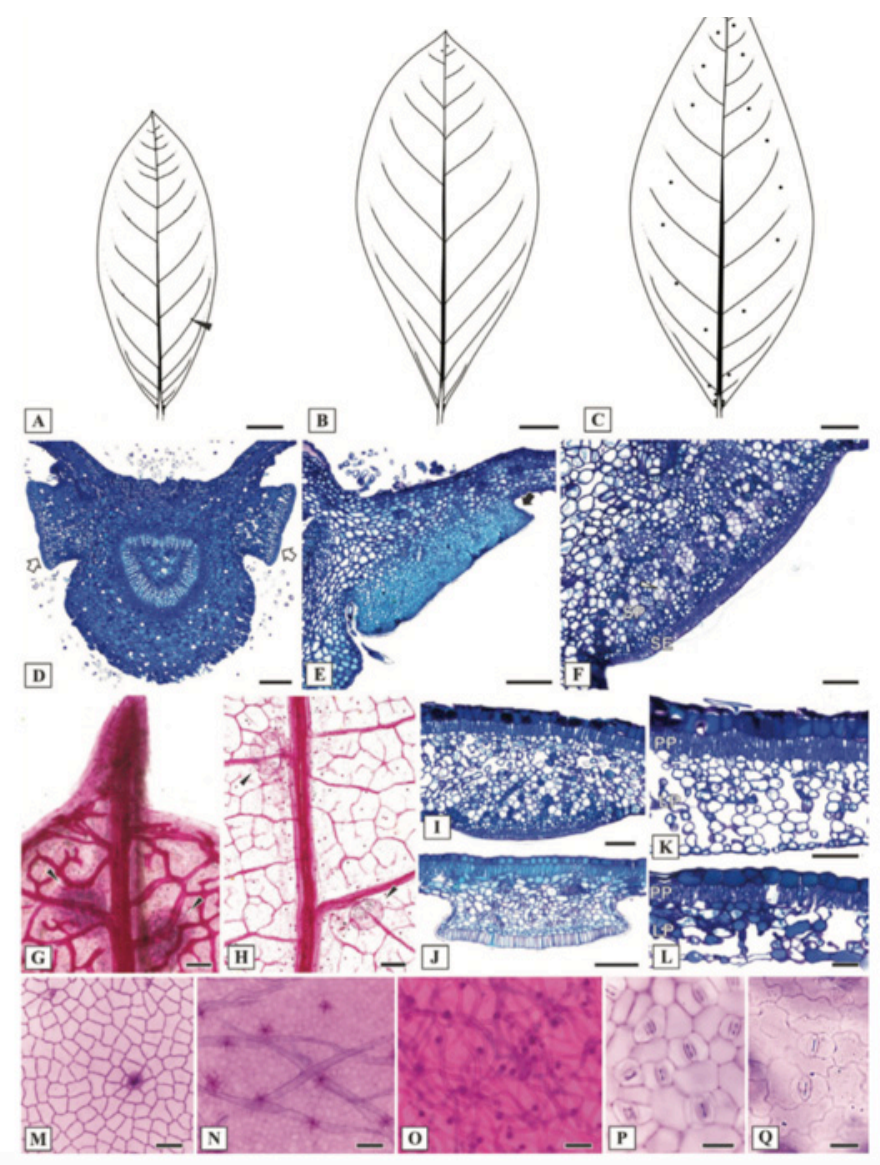

Fonte: ALMEIDA, R. F. et al. Taxonomic revision of Mcvaughia W.R Anderson (Malpighiaceae): notes on vegetative and reproductive anatomy and the description of a new species. Phytokeys 117: 45-72, 2019. 
Nos trechos acima, é possível observar que, enquanto os autores do artigo científico se preocupam com os detalhes dos métodos utilizados na pesquisa, o jornalista responsável pela matéria que foi publicada no Boletim UFMG está mais preocupado em contextualizar o estudo para o leitor, tentando explicar, em uma linguagem simples, como o trabalho foi feito.

Ainda na retranca "Cirurgião de plantas" (10), nos deparamos com a estratégia de variação na modalidade metáfora, em conjunto com a estratégia de expansão na modalidade citação (11). O título desta retranca usa a metáfora de cirurgião para explicar o trabalho do biólogo taxonomista: trata-se de um pesquisador que "opera" plantas. A associação se dá porque, assim como o cirurgião disseca corpos, o taxonomista dissecaria as plantas. Tal comparação não aparece no artigo científico, pois este explicita a pesquisa científica para leitores que são do campo de conhecimento do autor e, dessa forma, sabem como funciona o trabalho de um pesquisador taxonomista.

\section{(10) Cirurgião de plantas}

(11) A descrição é fundamentada em procedimentos manuais de dissecação de tecidos. "É como brincar de cirurgiã de plantas", compara Rafael Almeida.

Já na segunda retranca da matéria, sob o título "Pesquisa de base", podemos observar outro exemplo do fenômeno de expansão por citação. Em dois pequenos parágrafos, o jornalista aborda a importância de um estudo como este, que pode ser classificado como uma "pesquisa de base". Nestes parágrafos, o jornalista explicita, por meio das falas do pesquisador, que o Brasil concentra seus estudos do campo no bioma do cerrado, pois nele se encontram as maiores cidades do país. No que se refere à pesquisa de base, o jornalista usa a estratégia de expansão por citação para destacar a importância do estudo que foi retratada ao longo da matéria (12).

(12) "Seja para exploração econômica ou para a aplicação na medicina, é primordial saber o nome dos organismos que a natureza oferece”.

É importante apontarmos outro momento em que a estratégia de redução foi utilizada. $\mathrm{Na}$ primeira parte do texto jornalístico, observamos a estratégia de redução na modalidade resumo, quando o jornalista, em apenas um parágrafo, descreve a pesquisa que foi narrada nas 28 páginas do artigo científico (13). Neste momento, percebemos que a UFMG divulga o conhecimento produzido por seus pesquisadores por meio de textos jornalísticos que podem ser considerados resumos objetivos e inteligíveis das pesquisas que foram realizadas. A redução na modalidade resumo se torna, assim, uma estratégia usada pelo jornalista, visto que o Boletim UFMG não conta com espaço suficiente para descrever a pesquisa minunciosamente.

(13) O trabalho consistiu na revisão taxonômica do gênero Mcvaughia, incluindo descrições morfológicas completas, mapas de distribuição, ilustrações e notas sobre conservação, distribuição e etimologia das espécies.

Finalmente, destacamos uma estratégia de expansão que foi observada na matéria jornalística escolhida e que é comum a todas as matérias de ciência que são publicadas no Boletim UFMG. Ao final do texto, foi colocada uma espécie de ficha técnica sobre o artigo que deu origem à matéria. Nesta ficha (14), foram disponibilizadas as informações sobre a autoria do artigo e a revista científica onde ele foi publicado, além de um link que dá acesso a este texto. Por meio desta estratégia de expansão, o leitor do site tem acesso ao artigo científico na íntegra, caso tenha se interessado pela pesquisa retratada e queira ler mais sobre o assunto. 
(14) Artigo: Taxonomic revision of Mcvaughia W. R. Anderson (Malpighiaceae): notes on vegetative and reproductive anatomy and the description of a new species

Autores: Rafael Felipe de Almeida (UFMG), Isabel Guesdon e Renata Meira (Universidade Federal de Viçosa) e Marcelo Pace (universidad Nacional Autónoma de México)

Disponível em: phytokeys.pensoft.net/ article/32207/

\section{CONSIDERAÇÕES FINAIS}

Por meio da análise da matéria "Flor do Nordeste", publicada no Boletim UFMG, percebemos que a recontextualização é um processo complexo. No caso deste artigo, trabalhamos com a recontextualização de um texto escrito e que possui várias especificidades (o artigo científico) para outro texto escrito, também repleto de características próprias (a matéria jornalística).

A recontextualização se mostrou um processo capaz de mudar a linguagem de um texto de forma a torná-lo inteligível para um contexto distinto do seu contexto de produção. Quando falamos da divulgação científica que é realizada por meio do jornalismo científico, este processo é essencial para que a informação sobre ciência ultrapasse os muros das universidades, centros de pesquisa e laboratórios, chegando ao cidadão comum, maior interessado nas mudanças ocasionadas pelas descobertas e pesquisas sobre ciência e tecnologia.

Como pôde ser verificado, pudemos perceber que os procedimentos discursivos de recontextualização (adição, redução e variação) são capazes de tornar o discurso científico mais acessível ao leitor, fazendo com que assim seja alcançado o principal objetivo da divulgação científica. No caso do procedimento de redução, ele atua como uma espécie de filtro, usado pelo jornalista para escolher o que precisa/deve ser divulgado a respeito de uma pesquisa e o que é desnecessário, enquanto a adição e a variação aparecem como recursos que acrescentam e contextualizam informações que aproximam o tema da pesquisa científica do leitor do veículo jornalístico. Percebemos que as três estratégias, quando atuam juntas, são capazes de deslocar os temas das ciências, os transportando do contexto da pesquisa para o contexto da sociedade.

Vislumbramos a necessidade de estudos futuros sobre o letramento científico, que é a capacidade das pessoas compreenderem e interagirem em torno de conhecimentos especializados. Désirée Motta-Roth (2010) afirma que a ciência, como formação discursiva e ideológica e como esfera da atividade humana, depende de interlocutores que a desafiem, a alimentem e a derrubem, até que sejam criados novos paradigmas. Neste sentido, achamos que veículos especializados no jornalismo científico podem atuar neste letramento, criando condições para essa interação social.

Em se tratando do Boletim UFMG, pudemos perceber que este veículo jornalístico, além de divulgar o conhecimento científico que é produzido por seus pesquisadores, atua na promoção da imagem da universidade, ao mesmo tempo em que presta contas à sociedade. Percebemos, também, que a UFMG julga como importante que sua produção científica chegue até as pessoas, dedicando um espaço nobre de seus veículos jornalísticos a esse objetivo.

Neste artigo, reafirmamos a importância da divulgação científica para que o conhecimento produzido seja validado e utilizado pela sociedade. Esperamos que este trabalho lance luz ao modo como pesquisadores e jornalistas atuam juntos na divulgação do conhecimento científico e inspire outros trabalhos dedicados a estudar o modo como a divulgação da ciência tem papel importante no desenvolvimento de uma nação, na formação de uma cultura científica e no surgimento do pensamento crítico sobre temas relacionados à ciência. 


\section{REFERÊNCIAS}

ALMEIDA, R. F. Et al. Taxonomic revision of Mcvaughia W.R Anderson (Malpighiaceae): notes on vegetative and reproductive anatomy and the description of a new species. Phytokeys 117: 4572, 2019.

BERTOLLI, Filho C. Elementos para a prática do jornalismo científico. Biblioteca Online de Ciências da Comunicação, 2006. Disponível em < http:// www.bocc.ubi.pt/_esp/autor.php?codautor=939> Acesso em: 07 nov. 2014.

BUENO, Wilson da Costa. Jornalismo científico: conceitos e funções. Ciência e cultura, São Paulo, v.37, n.09, p. 1240-1247, 1985.

CALSAMIGLIA, H. Divulgar: itinerários discursivos del saber. Quark, Barcelona: Observatório de la comunicación científica, Universitat Pompeu Fabra, n. 7, p. 9-18, 1997.

CALSAMIGLIA, H.; CASSANY, D. Voces y conceptos en la divulgación científica. Revista Argentina de Linguística, Mendoza, n. 11-15, p. 173-209, 2001.

CASSANY, D. Análisis de la divulgación científica: modelo teórico y estratégias divulgativas. In: Texto, linguística y cultura. XIV Congreso de la Sociedad Chilena de Linguística. Comunicaciones seleccionadas. Osorno: Editorial Universidad de Los Lagos, 57-80, 2003.

CASSANY, D.; LÓPEZ, C. La transformación divulgativa de redes conceptuales científicas: hipótesis, modelo y estratégias. Discurso y sociedade, v.2, n.2, p. 73-103, 2000.

CIAPUSCIO, G. Linguística y divulgación de ciência. Quark, Barcelona: Observatório de la comunicación científica, Universitat Pompeu Fabra, n.7, p. 19-28, 1997.

ESPÍNDOLA, M. Flor do Nordeste. Boletim UFMG, Belo Horizonte, 22 abr. 2019, p. 4.
FOLHA DE S. PAULO. Manual de redação. São Paulo: PubliFolha, 2001.

MOTA-ROTH, Désirée. Sistemas de gêneros e recontextualização da ciência na mídia eletrônica. Gragoatá, Niterói, n. 28, p. 153-174, 2010.

NOCCIOLI, Carlos. A. M; CATALDI, Cristiane. $O$ ponto $G$ existe: A recontextualização do discurso sobre ciência na Superinteressante. Gláuks, v.11, n.1, p. 35-66, 2011.

SOUSA, J. P. Elementos de jornalismo impresso. Florianópolis: Letras contemporâneas - Oficina Editorial LTDA, 2005.

VAN LEEUWEN, T. Discourse and practice: new tools for critical discourse analysis. Oxford: Oxford University Press, 2008.

Submissão: maio de 2020-09-27 Aceite: setembro de 2020. 